\section{The Impact of the Location of Sepsis Presentation on Compli- ance to Centers for Medicare and Medicaid Services (CMS) Sepsis Core Measures: A Ret- rospective Cohort study}

\author{
Marwa Amer $^{1^{*}}$, Kellie Buschor ${ }^{2}$ and Martin J Ohlinger ${ }^{3}$ \\ ${ }^{1}$ Department of Pharmacy Services, King Faisal Hospital and Research \\ Center, Riyadh, Saudi Arabia
}

${ }^{2}$ Department of Pharmacy Practice, University of Toledo Medical Center, Toledo, Ohio, USA

${ }^{3}$ Director of Critical Care Pharmacy Residency, University of Toledo College of Pharmacy and Pharmaceutical Sciences, Toledo, Ohio, USA

\begin{abstract}
Objectives: In 2015, the Centers for Medicare and Medicaid Services implemented Severe Sepsis (SS) and Septic Shock (SSh) core measures. This study compared compliance to the measures between Emergency Department (ED) and Inpatients (IP). Secondary objectives included compliance to each bundle component, risk factors for noncompliance, hospital and ICU Length Of Stay (LOS), 30day mortality, and antibiotic initiation within one hour of presentation.

Methods: A retrospective, single-center and cohort study. Included patients with admission ICD code of SS and SSh between January 1 - June 30,2016 . Patients were excluded if they were less than 18 years of age, admitted with other types of shock (including cardiogenic shock, hemorrhagic shock and anaphylactoid reaction), pregnancy, expired within 6 hours of presentation, admitted to a hospice or palliative care/withdrawal of care before full therapy could be conducted, and transferred from another facility including transferred
\end{abstract}

*Corresponding author: Marwa Amer, Department of Pharmacy Services, King Faisal Hospital and Research Center, Riyadh, Kingdom Of Saudi Arabia, Tel: +966 114647272; E-mail: mra02834@sjfc.edu

Citation: Amer M, Buschor K, Ohlinger MJ (2018) The Impact of the Location of Sepsis Presentation on Compliance to Centers for Medicare and Medicaid Services (CMS) Sepsis Core Measures: A Retrospective Cohort Study. J Emerg Med Trauma Surg Care 5: 021

Received: November 11, 2017; Accepted: January 08, 2018; Published: January 26,2018 from outside hospitals, acute rehabilitation centers and Long Term Acute Care (LTAC) but not nursing homes or skilled nursing facilities. Patient information was accessed via electronic medical records.

Results: 272 encounters were screened; 118 were excluded. The 154 remaining subjects were distributed in a 2:1 ratio between ED and IP (ICUs and other hospital floors). For SS, overall 3-hour bundle compliance was $60.6 \%$ in ED vs. $34 \%$ in IP ( $P=0.003)$; and overall 6 -hour bundle compliance was $51 \%$ in ED vs. $25 \%$ in IP (P $=0.046$ ). There were no differences in 3 or 6 -hour bundle compliance for SSh. Comparing individual components, only the initial and repeated lactate rates were different: ED - $78.8 \%$ vs. IP - $46 \%$; $p<$ 0.001 , and ED - $51 \%$ vs. IP - $25 \% ; p=0.046$, respectively. Hospital and ICU LOS was shorter in the ED arm. Antibiotic initiation in one hour occurred more often in the IP arm ( $56 \%$ vs. $10.6 \%$; $P=0.001)$. 30-day mortality was not different.

Conclusion: In this study, core measure compliance is higher when sepsis presents in the ED. Utilizing such data will guide targeted efforts for sepsis bundles compliance.

Keywords: Centers for medicare and medicaid services; Emergency department; Intensive care unit; Sepsis; Septic shock; Severe sepsis; 3 Hours bundle; 6 Hours bundle.

\section{Abbreviations}

APACHE II: Acute Physiology and Chronic Health Evaluation score ARISE: Australasian Resuscitation in Sepsis Evaluation CMS: Centers for Medicare and Medicaid Services ED: Emergency Department EGDT: Early Goal-Directed Therapy

GCS: Glasgow Coma Scale

ICD-9: International Classification of Diseases, Ninth Revision codes ICU: Intensive Care Unit

IP: Inpatients

LOS: Length of stay

LTAC: Long Term Acute Care

MEWS: Modified Early Warning Scores

qSOFA: quick Sequential Organ Failure Assessment score

ProCESS: Protocol Based Care for Early Septic Shock

ProMISe: Protocolised Management in Sepsis

ScvO2: Central Venous Oxygen Measurement

SS: Severe Sepsis

SSh: Septic Shock

SSC: Surviving Sepsis Campaign

\section{Introduction}

The incidence and impact of severe sepsis is generally underappreciated; it is the $10^{\text {th }}$ leading cause of death in the United States, with an estimated 750,000 hospitalizations each year, a mortality rate of $30 \%-50 \%$, and costs the health care system an estimated $\$ 14.6$ billion each year $[1,2]$. With the incidence of severe sepsis increasing, there is an undeniable need for an early recognition and standardized treatment that is shown to improve outcomes in patients with severe sepsis and septic shock [3]. 
In October 2015, version 5.0b of the Centers for Medicare and Medicaid Services (CMS) and updated Surviving Sepsis Campaign (SSC) bundle were released addressing the importance of early management of patients with severe sepsis and septic shock [4-6]. Moreover, prior literature has demonstrated the association between SSC performance bundles compliance with reduction in mortality and better outcomes. A meta-analysis of 50 observational studies was conducted by Damiani E et al., showed that performance improvement programs were associated with increased compliance with the complete 6-hour bundle (OR $=4.12$ [95\% CI 2.95 - 5.76) and with a reduction in mortality $(\mathrm{OR}=0.66[0.61-0.72])[7]$. The Impress study was conducted by Rhodes A et al., and demonstrated overall compliance with the 3 hours bundle was $19 \%$ and 6 hours bundle was $36 \%$ and both associated with significant reduction in mortality compared to the non-compliant group $(\mathrm{P}<0.001)$ [8].

Furthermore, Levy and his colleague evaluated the compliance with the SSC performance bundles in subjects entered into the SSC database from 2005, through 2012 [9]. Patients from the Emergency Department (ED), medical and surgical wards and Intensive Care Unit (ICU) who met diagnosis criteria for severe sepsis and septic shock were included. The authors found that the median resuscitation bundle compliance rate was $15 \%$ with overall lower mortality was observed in high $(29.0 \%)$ versus low $(38.6 \%)$ resuscitation bundle compliance sites $(\mathrm{p}<0.001)$ and between high $(33.4 \%)$ and low $(32.3 \%)$ management bundle compliance sites $(\mathrm{p}=0.039)$.

Similarly, small and large groups independently collaborated to improve sepsis care [10,11]. The Michigan Health and Hospital Association Keystone Sepsis Collaborative evaluated the impact of a multi-ICU quality improvement collaborative implementing a protocol-based resuscitation bundle to treat septic shock patients based on eight bundle measures reflected the 2008 SSC guidelines. The evaluation found that high adherence collaborative hospitals had significant reductions in mortality (odds ratio, 0.84; 95\% CI, $0.79-0.93$; $\mathrm{p}<$ $0.001)$ and length of stay $(-0.7 \mathrm{~d} ; 95 \% \mathrm{CI},-1.1$ to $-0.2 ; \mathrm{p}<0.001)$ compared to non-collaborative hospitals [12]. Like Michigan, other states developed sepsis collaborative programs. New Jersey hospitals aligned to tackle sepsis mortality, reducing the rate by $11 \%$ in one year [13].

As shown in the previous studies, data exist, but are limited, for the association between compliance with the SSC performance bundles or CMS sepsis core measures and positive outcomes. We have not yet aware of clinical investigation assessing the impact of the location of sepsis presentation on compliance to CMS sepsis core measure. In our institution, despite the standardized measure to insure compliance with CMS and SSC performance bundles (i.e., a sepsis order set, Modified Early Warning Scores (MEWS) and rapid response teams), the implementation may vary depending on the location of the patient's first presentation with sepsis. In this context, we conducted a retrospective study with a primary objective to compare the overall compliance to the CMS sepsis core measure (version 5.0 b) between patients who presented with severe sepsis and septic shock in the ED versus those who are already hospitalized. We hypothesized that there will be a difference in the adherence to the core measure between patients who present with sepsis in the ED versus those who are already hospitalized.

\section{Methods}

\section{Study design}

This was a retrospective cohort study conducted at the University of Toledo Medical Center (UTMC), 320-Bed academic medical center, a level I trauma center and accredited primary stroke center. The institution consists of 25-bed ED, 18-bed MICU/Neurocritical Care Unit, 10-bed Surgical/Trauma ICU and 22-bed Cardiac Care Unit. The annual admissions around 11,390 admissions and emergency room have around 35,781 visits. This study was approved by the institutional review board with waiver for written informed consent. In addition, a survey was distributed to employees over a 2 month period (Feb 1 - March 31, 2017) and intended to identify risk factors for non-adherence to CMS sepsis core measure components as part of secondary outcomes. Survey monkey.com was used for administering the survey. The access to the survey monkey data was limited to the principle investigator and the co-investigator. The survey was anonymous and participation was voluntary. After submitting the survey, the respondents will not be able to re-access the survey. A pop-up message will appear stating that response already submitted to ensure each respondent will access and answer the survey once and no redundancy in participation. E-mail reminders were sent to participants to complete the survey during the 21 - day study period to increase study participation. The survey went through a multidisciplinary pilot phase prior to dissemination of the survey to address any potential problems. Data from the pilot phase were not included in the final results of the study. A copy of the survey is provided in Online Supplementary Appendix.

\section{Participants}

To be included, patients had to be 18 years or older and were identified via admission International Classification of Diseases, Ninth Revision (ICD-9) codes as having a severe sepsis and septic shock between January 1, 2016 and June 30, 2016. Patients were divided in 2:1 fashion between ED and inpatient (including ICU and other hospital floors), respectively. We chose 2:1 distribution as most of the diagnosed patients with sepsis at ED upon admission.

Patients were excluded if they were less than 18 years of age, admitted with other types of shock (including cardiogenic shock, hemorrhagic shock and anaphylactoid reaction), pregnancy, expired within 6 hours of presentation, admitted to a hospice or palliative care/ withdrawal of care before full therapy could be conducted, and transferred from another facility including transferred from outside hospitals, acute rehabilitation centers, and Long Term Acute Care (LTAC) but not nursing homes or skilled nursing facilities. To decrease the chance of the selection bias, each participant was evaluated for the inclusion and exclusion criteria independently by 2 reviewers. As for the survey participant, it was sent to the targeted 250 UTMC employees in ED and other hospital floors including the ICU floors.

\section{Outcomes definition}

The primary endpoint was to determine if there was a difference between the two arms in overall compliance to the CMS severe sepsis and septic shock 3 hours and 6 hours bundle (version 5.0b).

Secondary objectives included assessing the compliance rate to each individual component of the bundle based on location of sepsis presentation, identifying the risk factors for non-compliance, length of hospital and ICU stay, 30-day in-hospital mortality and the antibiotic initiation rate within the first hour of sepsis presentation. 
The following data were collected: demographic information (age, gender, race, height, weight, comorbidities), Glasgow Coma Scale (GCS), MEWS, components of the Acute Physiology and Chronic Health Evaluation score (APACHE II), quick Sequential Organ Failure Assessment score (qSOFA), location of sepsis identification, primary service, time zero, and 3 hours and 6 hours bundle components. The qSOFA, MEWS, GCS and APACHE scores were calculated at the time of development of sepsis. Time Zero was defined as the date and time on which the last vital sign/lab value of severe sepsis or septic shock inclusion was noted. Overall compliance to CMS 3 hours bundle for severe sepsis was defined as "all-or-none" compliance to the following components: initial lactate level collection, blood cultures collection and broad spectrum IV antibiotic(s) administration. If there were multiple lactate levels, we chose the level reported closest to the time zero. Acceptable antibiotics were assessed based on the CMS list of acceptable mono therapy and combination antibiotics therapy. The overall compliance to CMS 6 hours bundle for severe sepsis was defined as repeated lactate level measurement only if initial one is above 2. If there were multiple repeated lactate levels, we chose the repeated level reported closest to the time zero. We defined the overall compliance to CMS 3 hours bundle for septic shock as resuscitation with $30 \mathrm{ml} / \mathrm{kg}$ crystalloid fluids (including $0.9 \%$ sodium chloride, lactated ringers, or plasmalyte). We used the actual body weight documented closest and prior to the order for crystalloid fluids. Single order written for the entire $30 \mathrm{~mL} / \mathrm{kg}$ volume or multiple orders written for total $30 \mathrm{~mL} / \mathrm{kg}$ or more were included. If hypotension persists (either a $\mathrm{SBP}<90$ or a $\mathrm{MAP}<65$ or $>40 \mathrm{mmHg}$ decrease in $\mathrm{SBP}$ ) within one hour after fluid administration, we defined the overall compliance to CMS 6 hours bundle of septic shock as administration of vasopressors and repeating focused exam or volume status/tissue perfusion assessment. Acceptable vasopressors were assessed based on CMS list. Repeated focused exam was defined as all of the following: vitals, cardiopulmonary exam, capillary refill, peripheral pulse evaluation and skin exam. Volume Status and tissue perfusion included 2 of the following: bedside cardiovascular ultrasound, CVP, Central Venous Oxygen measurement (ScvO2), passive leg raise or fluid challenge (500 $\mathrm{ml}$ over $15 \mathrm{~min}$ or $1000 \mathrm{ml}$ over $30 \mathrm{~min}$ ).

\section{Statistical analysis}

In previous studies, $20 \%$ compliance rate was considered appropriate $[14,15]$. Assuming this compliance rate, a relative difference of $30 \%$ between the two treatment groups with $80 \%$ power and $5 \% \alpha$ would require at least 150 total subjects after accounting for the 2:1 ED/IP allocation. Nominal data were analyzed using either Fisher's exact test or X2 test, as appropriate, and continuous data was reported using Student's t test or Mann-Whitney U test, as appropriate. Assessment of normality was done using the Shapiro-Wilk test. All tests of significance were two-tailed, and $\mathrm{p}<0.05$ was considered statistically significant. Results were presented as n (\%) or median (Inter Quartile Range [IQR]) when in tabular format. All statistics were calculated using SPSS Version 23 (SPSS IBM, New York, NY).

\section{Results}

During the study period, a total of 272 encounters were screened and 118 encounters excluded. Charts were reviewed for 154 patients who met the inclusion criteria (Figure 1).

The inpatient arm further divided into different primary admitting services with a majority presented by internal medicine, followed by Medical ICU and Surgical ICU (Figure 2).
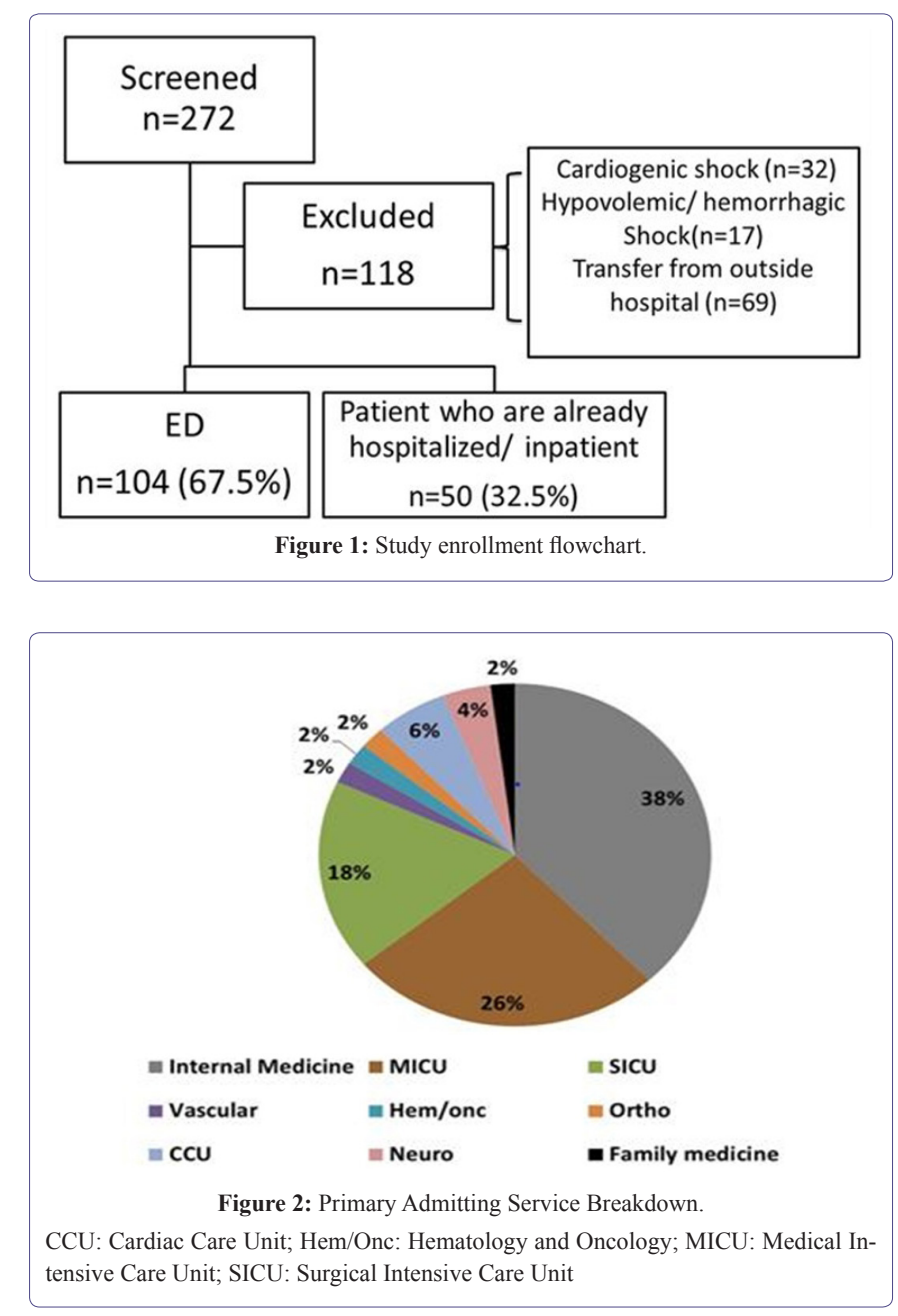

Baseline characteristics were similar between the groups with a few notable exceptions (Table 1). In the inpatient arm, septic shock and malignancy were significantly more frequent than in the ED arm $(\mathrm{p}<0.05)$.

The primary outcome of overall 3 hours bundle compliance occurred more frequently in ED, $60.6 \%$ vs. IP, $34 \% ; p=0.003$ for severe sepsis. Overall 6 hours bundle compliance for severe sepsis occurred more frequently in ED, $51 \%$ vs. IP, $25 \%$; $=0.046$. No statistical significant difference was noted in overall 3 and 6 hours bundle compliance for septic shock (Table 2).

Looking at the individual bundle components, the majority of non-compliance identified in the initial and repeated lactate rates: ED - $78.8 \%$ vs. IP - $46 \%$; $<<0.001$, and ED - $51 \%$ vs. IP - $25 \%$; $=$ 0.046 , respectively) (Table 2).

Median hospital and ICU LOS was significantly shorter in the ED, 6 days [IQR 5 - 10.8]) vs. IP, 10 days [IQR 6-18]; $\mathrm{p}=0.001$, and ED 0 days [IQR 0 - 4] vs. IP 3 days [IQR $0-8$ ]; $p=0.014$, respectively. Thirty day in hospital mortality was $19.2 \%$ in ED group vs.30\% in inpatient group, but this did not reach statistical significance ( $\mathrm{P}$ $=0.153)$. Interestingly, the inpatient arm was more likely to initiate antibiotics within the first hour compared to ED (56\% vs. $10.6 \%$; P $=0.001)$. 


\begin{tabular}{|c|c|c|c|}
\hline Characteristic & $\begin{array}{c}\text { ED n=104 } \\
\mathbf{( 6 7 . 5 \% )}\end{array}$ & $\begin{array}{c}\text { Inpatients n=50 } \\
\mathbf{( 3 2 . 5 \% )}\end{array}$ & P-value \\
\hline Age, Years & $60(50-72.5)$ & $65(54.8-74.5)$ & 0.53 \\
\hline Weight, kilo gram & $80.9(65-102)$ & $81.4(68.1-105)$ & 0.765 \\
\hline Height, Inch & $67(63.3-70.8)$ & $66(63-69.3)$ & 0.532 \\
\hline Male Sex & $62(59.6)$ & $28(56)$ & 0.67 \\
\hline White Race & $75(72.1)$ & $32(64)$ & 0.501 \\
\hline Srcr on admission, mg/dL & $1.5(0.9-3.1)$ & $1.6(0.87-2.3)$ & 0.531 \\
\hline GCS & $15(10-15)$ & $15(13.8-15)$ & 0.092 \\
\hline qSOFA & $1(1-2)$ & $1(0-2)$ & 0.003 \\
\hline MEWS & $3.5(2-5)$ & $4(2-6)$ & 0.332 \\
\hline APACHE II & $17(12-22.8)$ & $14.5(10-20.3)$ & 0.088 \\
\hline Severe Sepsis & $101(97.1)$ & $48(96)$ & 0.66 \\
\hline Septic Shock & $15(14.4)$ & $22(44)$ & $<0.001$ \\
\hline Diabetes mellitus & $49(47.1)$ & $25(50)$ & 0.863 \\
\hline Hypertension & $73(70.2)$ & $29(58)$ & 0.149 \\
\hline Cardiovascular diseases & $42(40.4)$ & $27(54)$ & 0.122 \\
\hline Congestive heart failure & $16(15.4)$ & $12(24)$ & 0.264 \\
\hline Anemia & $29(28.2)$ & $29(58)$ & 0.001 \\
\hline CVA & $22(21.2)$ & $12(24)$ & 0.684 \\
\hline Malignancy & $17(16.3)$ & $16(32)$ & 0.036 \\
\hline AB within 3 months & $29(27.9)$ & $14(28)$ & 1 \\
\hline Transplant & $5(4.8)$ & $1(2)$ & 0.664 \\
\hline Prednisone prior to admission & $14(13.5)$ & $3(6)$ & 0.271 \\
\hline & &
\end{tabular}

Table 1: Baseline Characteristics. $\dagger$

APACHE $=$ Acute Physiology and Chronic Health Evaluation; CVA: Cerebral Vascular Accident; GCS: Glasgow Coma Scale; MEWS: Modified Early Warning Score $\dagger$ : Values represented as $\mathrm{n}(\%)$ or median (IQR) as appropriate

The survey data included a total of 96 responders $(8$ in ED, 88 in inpatient). In summary, participants were predominately MD residents, fellows and nurses. Approximately, $61.4 \%$ in the inpatient arm indicated familiarity with our institution sepsis order set (sepsis iform) compared to $100 \%$ in the ED arm. Of those in the ED arm, $37.5 \%$ indicated familiarity with ED specific sepsis order set (ED sepsis iform) compared to $17 \%$ in the inpatient arm. Per supplementary index (Supplementary table 1), respondents were asked question regarding familiarity of SIRS criteria and qSOFA criteria. Approximately, a total of three-quarters of respondents indicated that systolic blood pressure $<90 \mathrm{mmHg}$ is one of the SIRS criteria while it is not $(75 \%$ in ED vs. $72.7 \%$ in inpatients). The majority of inpatient respondents chose heart rate above 90 Beats Per Minute (BPM) as one of the qSOFA criteria while it is not $(25 \%$ in ED vs. $86.7 \%$ in inpatients). Table 2 of the supplementary index contains the responses in details for the 5 remaining questions.

\section{Discussion}

To the best of our knowledge, this is the first study to evaluate the impact of the location of sepsis presentation on compliance to CMS sepsis core measure. We found statistical significant differences in the overall 3 and 6 hours bundle compliance for severe sepsis in ED vs. inpatient but no statistical significant difference was noted in overall 3 and 6 hours bundle compliance for septic shock. As indicated in the survey, common barriers in the inpatient arm included delaying in identifying septic patients and knowledge deficit, which are similar to barriers reported in the previous studies [14-16]. An important consideration in interpreting these results is that bundle compliance is defined as "all-or-none". Noncompliant group patients may receive care that includes a majority, or even totality of bundle elements, just not in adherence to the time goals. Moreover, it seems that the higher rates of bundle compliance observed in ED arm may be due to the difference in nursing to provider ratios in the ED compared to IP units. Also, patients with severe sepsis or septic shock in ED arm are usually identified at ED triage vs. delays to identification on the inpatient side and potentially staffing differences, which would be the primary rationale for our findings.

\begin{tabular}{|c|c|c|c|}
\hline Bundle Components & $\begin{array}{c}\text { ED n }=104 \\
(67.5 \%)\end{array}$ & $\begin{array}{c}\text { Inpatients n }=50 \\
(32.5 \%)\end{array}$ & $P$ - value \\
\hline \multicolumn{4}{|c|}{ Overall 3 hours Bundle Compliance (\%) } \\
\hline Severe sepsis & 60.6 & 34 & 0.003 \\
\hline Septic Shock & 33.3 & 18.2 & 0.438 \\
\hline \multicolumn{4}{|c|}{ Overall 6 hours Bundle Compliance (\%) } \\
\hline Severe sepsis & 51 & 25 & 0.046 \\
\hline Septic Shock & 63 & 60 & 1 \\
\hline \multicolumn{4}{|c|}{ Individual Component of 3 hours Bundle Compliance (\%) } \\
\hline Initial lactate collection & 78.8 & 46 & $<0.001$ \\
\hline Blood culture collection & 91.3 & 84 & 0.181 \\
\hline Initial broad spectrum IV antibiotics & 75 & 74 & 1 \\
\hline $\begin{array}{c}30 \mathrm{ml} / \mathrm{kg} \text { crystalloid fluid } \\
\text { administration if septic shock }\end{array}$ & 40 & 45.5 & 1 \\
\hline $\begin{array}{c}30 \mathrm{ml} / \mathrm{kg} \text { crystalloid fluid } \\
\text { administration for hypotension or } \\
\text { lactate } \geq 4 \mathrm{mmol} / \mathrm{L} \dagger\end{array}$ & 28.1 & 35.7 & 0.482 \\
\hline \multicolumn{4}{|c|}{ Individual Component of 6 hours Bundle Compliance (\%) } \\
\hline Repeated lactate if initial one $>2$ & 51 & 25 & 0.046 \\
\hline Vasopressors administration & 86.7 & 86.4 & 1 \\
\hline Repeated focused exam & 46.7 & 36.4 & 0.734 \\
\hline $\begin{array}{c}\text { Volume status/ tissue perfusion } \\
\text { assessment }\end{array}$ & 40 & 45.5 & 1 \\
\hline
\end{tabular}

Table 2: Overall and individual component of 3 and 6 hours bundle compliance rate. $\dagger$ : There are slight differences between the updated SSC bundle and CMS version $5.0 \mathrm{~b}$ bundle in fluid administration. SCC bundle included administration of $30 \mathrm{ml} /$ $\mathrm{kg}$ crystalloid for hypotension or lactate $\geq 4 \mathrm{mmol} / 1$ while CMS version $5.0 \mathrm{~b}$ bundle requires the resuscitation with $30 \mathrm{ml} / \mathrm{kg}$ crystalloid fluids within three hours of presentation ONLY if Septic Shock present.

Compared to Rhodes et al., and Levy et al., we observed higher rate of compliance to 3 and 6 hours bundle and no statistically significant differences found with 30 days in-hospital mortality $[8,9]$. However, there was a lower mortality rate observed in ED group (higher compliant group) compared to the inpatient arm which still be deemed clinically relevant. Although APACHE II scores were not significantly different between groups, the IP arm had significantly higher rates of septic shock and these patients may be more likely to expire. Therefore, the observed benefits of bundle compliance may even be understated in the IP arm.

We also found that the inpatient arm was more likely to initiate antibiotics within the first hour compared to ED. This could be intuitive as sicker patients are more easily identified and subsequently may be more likely to receive antibiotic sooner. Additionally, the difference in antibiotic initiation time could be partially related to the difference in medication distribution at medication dispensing cabinet among different hospital areas in our institution. 
Citation: Amer M, Buschor K, Ohlinger MJ (2018) The Impact of the Location of Sepsis Presentation on Compliance to Centers for Medicare and Medicaid Services (CMS) Sepsis Core Measures: A Retrospective Cohort Study. J Emerg Med Trauma Surg Care 5: 021.

We also noted lower rate of $30 \mathrm{ml} / \mathrm{kg}$ crystalloid fluid administration in both groups. This could partially explain by presence of congestive heart failure (15.4\% in ED and $24 \%$ in inpatients) and renal failure (baseline serum creatinine 1.5; IQR 0.9 - 3.1 in ED and 1.6; IQR $0.87-2.3$ in inpatients) as possible comorbidities in our study population. Considering clinical concern for aggressive fluid administration for these patients as shown by Jaffee and his colleagues, further investigation in these populations is warranted [17].

Limitations of our study included a single institution experience and small sample size which may limit the external validity, and power analysis was based on theoretical difference of compliance rate reported in the previous studies between ED and other hospital floors. In addition, we used admission ICD-9 codes to identify patients with severe sepsis and septic shock which do not necessarily in line with the new Sepsis-3 consensus definitions [18,19] or the definitions used in EGDT, ProCESS, ARISE and ProMISe [20-25]. Also, we did not conduct a cost-effectiveness analysis to determine the cost savings associated with the bundle compliance and we did not assess the impact of using CMS antibiotics list on drug resistance organisms. Recently, multi stakeholder work group composed of a representative from the Society of Critical Care Medicine, Infectious Diseases Society of America, American College of Emergency Physicians and the Society of Hospital Medicine recommended a revision for the CMS SEP-1 antibiotic tables in alignment with prudent antimicrobial stewardship [26]. Therefore, further investigation in this area is warranted. We also used the CMS sepsis core measure version $5.0 \mathrm{~b}$ as this aligns with our study period while more updated CMS sepsis core measure has been released since then [4]. Finally, we acknowledged the difference in the baseline characteristic between the two cohorts; however, this study is considered a foundation for future trials to determine whether location of sepsis presentation is an independent predictor of compliance with these CMS measures with an adjustment for the confounders and over a longer period to mitigate any seasonal effects.

Limitations of our survey include a small response rate and more specifically in the ED arm with 8 respondents versus 88 inpatient respondents indicating a clearly disproportionate higher number from the IP cohort and possibilities of selection bias and may cause the reader to be skeptical of the survey results.

Our future directions included utilizing sepsis alerts more often in inpatients to identify patients who meet the sepsis criteria faster, streamlining the process of patient transfer from ED to the inpatients through a handoff transfer tool, and conducting educational sessions for sepsis core measures to keep up-to-date with the new version 5.2a CMS bundle. Daily huddles for feedback on sepsis bundle success or failures within the past 24 hours are also being considered.

\section{Conclusion}

It appears that compliance to CMS sepsis core measures is higher when sepsis first presents in the ED. Utilizing such data will guide targeted efforts for improvement of compliance to 3 hours and 6 hours bundle for severe sepsis and septic shock in all areas, but with special focus on inpatient identification of new sepsis or septic shock diagnoses.

\section{Acknowledgments}

The authors would like to thank Kelli Cole, Brian Hoffman, John Macko, Dagmar Martin and Pamela Venglarcik for their participation in this study.

\section{References}

1. Dellinger RP, Levy MM, Rhodes A, Annane D, Gerlach H, et al. (2013) Surviving Sepsis Campaign: International guidelines for management of severe sepsis and septic shock: 2012. Crit Care Med 41: 580-637.

2. Hall MJ, Williams SN, DeFrances CJ, Golosinskiy A (2011) Inpatient care for septicemia or sepsis: a challenge for patients and hospitals. NCHS Data Brief 1-8.

3. Angus DC, Linde-Zwirble WT, Lidicker J, Clermont G, Carcillo J, et al. (2001) Epidemiology of severe sepsis in the United States: analysis of incidence, outcome, and associated costs of care. Crit Care Med 29: 1303-1310.

4. https://www.qualitynet.org/dcs/ContentServer?c=Page\&pagename $=$ QnetPublic\%2FPage\%2FQnetTier3\&cid=1228775749207

5. Faust JS, Weingart SD (2017) The Past, Present, and Future of the Centers for Medicare and Medicaid Services Quality Measure SEP-1: The Early Management Bundle for Severe Sepsis/Septic Shock. Emerg Med Clin North Am 35: 219-231.

6. Dellinger RP, Schorr CA, Levy MM (2017) A users' guide to the 2016 Surviving Sepsis Guidelines. Intensive Care Med 43: 299-303.

7. Damiani E, Donati A, Serafini G, Rinaldi L, Adrario E, et al. (2015) Effect of Performance Improvement Programs on Compliance with Sepsis Bundles and Mortality: A Systematic Review and Meta-Analysis of Observational Studies. PLoS One 10: 0125827.

8. Rhodes A, Phillips G, Beale R, Cecconi M, Chiche JD, et al. (2015) The Surviving Sepsis Campaign bundles and outcome: results from the International Multicentre Prevalence Study on Sepsis (the IMPreSS study). Intensive Care Med 41: 1620-1628.

9. Levy MM, Rhodes A, Phillips GS, Townsend SR, Schorr CA, et al. (2014) Surviving Sepsis Campaign: association between performance metrics and outcomes in a 7.5-year study. Intensive Care Med 40: 16231633.

10. Schorr C, Odden A, Evans L, Escobar GJ, Gandhi S, et al. (2016) Implementation of a multicenter performance improvement program for early detection and treatment of severe sepsis in general medical-surgical wards. J Hosp Med 11: 32-39.

11. Leisman D, Bianculli A, Doerfler ME, Gribben J, Andersen R, et al. (2016) Survival benefit and cost savings from emergency department compliance with a basic 3-hour sepsis bundle in a multisite, prospective, observational study. Academic Emergency Medicine 23: 18.

12. Thompson MP, Reeves MJ, Bogan BL, DiGiovine B, Posa PJ, et al. (2016) Protocol-based resuscitation bundle to improve outcomes in septic shock patients: evaluation of the Michigan Health and Hospital Association Keystone Sepsis Collaborative. Crit Care Med 44: 2123-2130.

13. Stainton LH (2016) NJ hospitals join forces to reduce deaths caused by sepsis. NJ Spotlight, New Jersey, USA.

14. Carlbom DJ, Rubenfeld GD (2007) Barriers to implementing protocolbased sepsis resuscitation in the emergency department-results of a national survey. Crit Care Med 35: 2525-2532.

15. Burney M, Underwood J, McEvoy S, Nelson G, Dzierba A, et al. (2012) Early detection and treatment of severe sepsis in the emergency department: Identifying barriers to implementation of a protocol-based approach. J Emerg Nurs 38: 512-517.

16. Jones AE, Kline JA (2005) Use of goal-directed therapy for severe sepsis and septic shock in academic emergency departments. Crit Care Med $33: 1888-1890$.

17. Jaffee W, Hodgins S, McGee WT (2017) Tissue Edema, Fluid Balance, and Patient Outcomes in Severe Sepsis: An Organ Systems Review. J Intensive Care Med. 
18. Seymour CW, Liu VX, Iwashyna TJ, Brunkhorst FM, Rea TD, et al. (2016) Assessment of clinical criteria for sepsis: for the third international consensus definition for sepsis and septic shock (Sepsis-3). JAMA 315: $762-774$.

19. Singer M, Deutschman CS, Seymour CW, Shankar-Hari M, Annane D, et al. (2016) The third international consensus definitions for sepsis and septic shock (Sepsis-3). JAMA 315: 801-810.

20. Rivers E, Nguyen B, Havstad S, Ressler J, Muzzin A, et al. (2001) Early goal-directed therapy in the treatment of severe sepsis and septic shock. N Engl J Med 345: 1368-1377.

21. ARISE Investigators, ANZICS Clinical Trials Group, Peake SL, Delaney A, Bailey M et al. (2014) Goal-Directed Resuscitation for Patients with Early Septic Shock. N Engl J Med 371: 1496-1506.

22. Power GS, Harrison DA, Mouncey PR, Osborn TM, Harvey SE, et al. (2013) The Protocolised Management in Sepsis (ProMISe) trial statistical analysis plan. Crit Care Resusc 15: 311-317.
23. ProCESS Investigators, Yealy DM, Kellum JA, Huang DT, Barnato AE, et al. (2014) A Randomized Trial of Protocol-Based Care for Early Septic Shock. N Engl J Med 370: 1683-1693.

24. Park SK, Shin SR, Hur M, Kim WH, Oh EA, et al. (2017) The effect of early goal-directed therapy for treatment of severe sepsis or septic shock: A systemic review and meta-analysis. J Crit Care 38: 115-122.

25. PRISM Investigators, Rowan KM, Angus DC, Bailey M, Barnato AE, et al. (2017) Early, Goal-Directed Therapy for Septic Shock - A Patient-Level Meta-Analysis. N Engl J Med 376: 2223-2234.

26. Septimus EJ, Coopersmith CM, Whittle J, Hale CP, Fishman NO, et al. (2017) Sepsis National Hospital Inpatient Quality Measure (SEP-1): Multistakeholder WorkGroup Recommendations for Appropriate Antibiotics for the Treatment of Sepsis. Clin Infect Dis 65: 1565-1569. 
Citation: Amer M, Buschor K, Ohlinger MJ (2018) The Impact of the Location of Sepsis Presentation on Compliance to Centers for Medicare and Medicaid Services (CMS) Sepsis Core Measures: A Retrospective Cohort Study. J Emerg Med Trauma Surg Care 5: 021.

\begin{tabular}{|c|c|}
\hline Questions & Choices \\
\hline 1. What is your role at UTMC? & $\begin{array}{ll}\text { - } & \text { Attending Physician } \\
\text { - } & \text { Registered Nurse } \\
\text { - } & \text { Resident Physician } \\
\text { - } & \text { Other (please specify) }\end{array}$ \\
\hline 2. Where you do currently employed? (for resident, what is your current rotation) & $\begin{array}{ll}\cdot & \text { ED } \\
\cdot & \text { Other (please specify) }\end{array}$ \\
\hline 3. Have you heard of the UTMC sepsis iform? & $\begin{array}{ll}\cdot & \text { Yes } \\
\text { - } & \text { No }\end{array}$ \\
\hline $\begin{array}{l}\text { 4. Did you know UTMC has a separate sepsis iform for the emergency department and for } \\
\text { inpatient use? }\end{array}$ & $\begin{array}{ll}\cdot & \text { Yes } \\
\cdot & \text { No }\end{array}$ \\
\hline $\begin{array}{l}\text { 5. Which of the following are included in the SIRS (systemic inflammatory response } \\
\text { syndrome) criteria? (Check all that apply) }\end{array}$ & $\begin{array}{ll}\text { - } & \mathrm{HR}>90 \mathrm{bpm} \\
\text { - } & \mathrm{SBP}<90 \mathrm{mmHg} \\
\text { - } & \mathrm{WBC}<4000 \text { or }>12000 \\
\text { - } & \text { Temperature }<36^{\circ} \mathrm{C} \text { or }>38.3^{\circ} \mathrm{C}\end{array}$ \\
\hline $\begin{array}{l}\text { 6. Which of the following are included in the qSOFA (quick sepsis related organ failure } \\
\text { assessment) score? (Check all that apply) }\end{array}$ & $\begin{array}{ll}\text { - } & \text { Altered mentation } \\
\text { - } & \mathrm{HR}>90 \mathrm{bpm} \\
\text { - } & \mathrm{SBP}<100 \mathrm{mmHg} \\
\text { - } & \text { Respiratory rate }>22 \text { breaths per minute }\end{array}$ \\
\hline $\begin{array}{l}\text { 7. How much crystalloid fluid would you administer to the severely septic/septic shock } \\
\text { patient? }\end{array}$ & 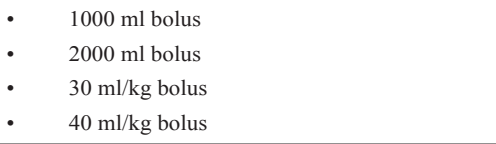 \\
\hline 8. Blood cultures should be drawn within what time frame of sepsis onset? & $\begin{array}{ll}\cdot & 1 \text { hour } \\
\text { - } & 3 \text { Hours } \\
\text { - } & 6 \text { Hours } \\
\text { - } & 24 \text { Hours }\end{array}$ \\
\hline $\begin{array}{l}\text { 9. What is the minimum initial lactate level that warrants a recheck of lactate level within } \\
6 \text { hours? }\end{array}$ & $\begin{array}{ll}\text { - } & 1 \mathrm{mmol} / \mathrm{L} \\
\text { - } & 2 \mathrm{mmol} / \mathrm{L} \\
\text { - } & 3 \mathrm{mmol} / \mathrm{L} \\
\text { - } & 4 \mathrm{mmol} / \mathrm{L}\end{array}$ \\
\hline $\begin{array}{l}\text { 10. Broad spectrum antimicrobials should be initiated within what time frame of sepsis } \\
\text { onset? }\end{array}$ & $\begin{array}{ll}\cdot & 1 \text { hour } \\
\text { - } & 3 \text { hours } \\
\text { - } & 6 \text { hours } \\
\text { - } & 24 \text { hours }\end{array}$ \\
\hline $\begin{array}{l}\text { 11. In your experience, what is the greatest contributor to delays in treatment of severe } \\
\text { sepsis and septic shock in our institution? }\end{array}$ & $\begin{array}{ll}\text { - } & \text { Lack of recognition of potential sepsis in } \\
\text { triage } \\
\text { - } & \text { Delay in diagnosis of sepsis by physicians } \\
\text { - } & \begin{array}{l}\text { Knowledge deficit regarding appropriate } \\
\text { management }\end{array} \\
\text { - } & \text { Nursing delays (time to completion of orders) } \\
\text { - } & \text { Pharmacy delays } \\
\text { - } & \text { Lab delays } \\
\text { - } & \text { Delay in availability of ICU beds }\end{array}$ \\
\hline
\end{tabular}

Table 1: Supplementary Online: Survey questioner. 
Citation: Amer M, Buschor K, Ohlinger MJ (2018) The Impact of the Location of Sepsis Presentation on Compliance to Centers for Medicare and Medicaid Services (CMS) Sepsis Core Measures: A Retrospective Cohort Study. J Emerg Med Trauma Surg Care 5: 021.

\begin{tabular}{|c|c|c|}
\hline & ED & Inpatients \\
\hline \# of responses & 8 & 88 \\
\hline MD residents and Fellow & 7 & 25 \\
\hline Registered Nurse & 1 & 63 \\
\hline Familiarity with UTMC sepsis iform & $8(100 \%)$ & $54(61.4 \%)$ \\
\hline Familiarity with UTMC ED specific sepsis & $3(37.5 \%)$ & $15(17 \%)$ \\
\hline \multicolumn{3}{|l|}{ Familiarity with SIRS criteria (Check all that apply) } \\
\hline $\mathrm{HR}>90 \mathrm{bpm}$ & $7(87.5 \%)$ & $65(73.9 \%)$ \\
\hline $\mathrm{SBP}<90 \mathrm{mmHg}$ & $6(75 \%)$ & $64(72.7 \%)$ \\
\hline $\mathrm{WBC}<4000$ or $>12000$ & $6(75 \%)$ & $58(66 \%)$ \\
\hline Temperature $<36^{\circ} \mathrm{C}$ or $>38.3^{\circ} \mathrm{C}$ & $7(87.5 \%)$ & $73(83 \%)$ \\
\hline \multicolumn{3}{|l|}{ Familiarity with qSOFA criteria (Check all that apply) } \\
\hline Altered mentation & $7(87.5 \%)$ & $73(83 \%)$ \\
\hline $\mathrm{HR}>90 \mathrm{bpm}$ & $2(25 \%)$ & $50(86.8 \%)$ \\
\hline $\mathrm{RR}>22 \mathrm{bpm}$ & $5(62.5 \%)$ & $66(75 \%)$ \\
\hline $\mathrm{SBP}<100 \mathrm{mmHg}$ & $6(75 \%)$ & $57(64.7 \%)$ \\
\hline \multicolumn{3}{|l|}{ Familiarity with crystalloid fluid Load } \\
\hline $1000 \mathrm{ml}$ bolus & $1(14.3 \%)$ & $16(18.2 \%)$ \\
\hline $2000 \mathrm{ml}$ bolus & $0(0 \%)$ & $11(12.5 \%)$ \\
\hline $30 \mathrm{ml} / \mathrm{kg}$ bolus & $7(87.5 \%)$ & $48(54.5 \%)$ \\
\hline $40 \mathrm{ml} / \mathrm{kg}$ bolus & $0(0 \%)$ & $13(14.8 \%)$ \\
\hline \multicolumn{3}{|l|}{ Familiarity with time frame when Blood cultures should be drawn } \\
\hline 1 hour & $6(75 \%)$ & $61(68.3 \%)$ \\
\hline 3 Hours & $1(12.5 \%)$ & $20(22.7 \%)$ \\
\hline 6 Hours & $1(12.5 \%)$ & $5(5.6 \%)$ \\
\hline 24 Hours & $0(0 \%)$ & $3(3.4 \%)$ \\
\hline \multicolumn{3}{|c|}{$\begin{array}{l}\text { Familiarity with minimum initial lactate level that warrants a recheck of lactate level } \\
\text { within } 6 \text { hours? }\end{array}$} \\
\hline $1 \mathrm{mmol} / \mathrm{L}$ & $0(\%)$ & $13(14.8 \%)$ \\
\hline $2 \mathrm{mmol} / \mathrm{L}$ & $6(75 \%)$ & $46(52.3 \%)$ \\
\hline $3 \mathrm{mmol} / \mathrm{L}$ & $1(12.5 \%)$ & $17(19.3 \%)$ \\
\hline $4 \mathrm{mmol} / \mathrm{L}$ & $1(12.5 \%)$ & $12(13.6 \%)$ \\
\hline \multicolumn{3}{|c|}{ Familiarity with time frame when broad spectrum antimicrobials should be initiated } \\
\hline 1 hour & $5(62.5 \%)$ & $44(50.0 \%)$ \\
\hline 3 hours & $1(12.5 \%)$ & $31(35.2 \%)$ \\
\hline 6 hours & $1(12.5 \%)$ & $11(12.5 \%)$ \\
\hline 24 hours & $1(12.5 \%)$ & $2(2.3 \%)$ \\
\hline \multicolumn{3}{|c|}{$\begin{array}{l}\text { In your experience, what is the greatest contributor to delays in treatment of severe sepsis } \\
\text { and septic shock in our institution? (Check all that apply) }\end{array}$} \\
\hline Lack of recognition of potential sepsis in triage & $5(62.5 \%)$ & $47(53.4 \%)$ \\
\hline Delay in diagnosis of sepsis by physicians & $2(25 \%)$ & $46(52.3 \%)$ \\
\hline Knowledge deficit regarding appropriate management & $2(25 \%)$ & $39(44.3 \%)$ \\
\hline Nursing delays (time to completion of orders) & $5(62.5 \%)$ & $31(35.2 \%)$ \\
\hline Pharmacy delays & $2(25 \%)$ & $32(36.4 \%)$ \\
\hline Lab delays & $6(75 \%)$ & $40(45.5 \%)$ \\
\hline Delay in availability of ICU beds & $0(0 \%)$ & $19(21.6 \%)$ \\
\hline
\end{tabular}

Table 2: Supplementary Online: Survey responses. 